\title{
Replies
}

\author{
Annalisa Coliva
}

Received: 21 August 2012 / Accepted: 13 September 2012 /

Published online: 19 October 2012

(C) Springer Science+Business Media Dordrecht 2012

Let me start by thanking all contributors for their tremendously interesting comments on my book, which raise extremely subtle issues regarding the exegesis of both G. E. Moore's work and of Wittgenstein's On Certainty (1969) and their significance for contemporary epistemology. In the following I will try to elucidate my own views, when I think they have been slightly misunderstood, no doubt because I myself haven't been clear enough in the book, and to defend the overall interpretation I have proposed. I will also try to highlight the relevance of the issues debated for current research in this area of philosophy.

However, I would like to stress a methodological point from the start. I think that both Moore's epistemological essays and, in particular, Wittgenstein's On Certainty are extremely complex, non-univocal texts. They often offer no obvious single picture about many of the numerous issues they deal with. This doesn't mean that all possible interpretations are on a par. Some have indeed more textual evidence on their side, some are more inherently coherent and some others are more fruitful than their competitors, insofar as they may be developed into systematic philosophical positions, which can be of interest to contemporary epistemology. I think, for instance, that, concerning On Certainty, Michael Williams' (2004) and Crispin Wright's (2004) readings belong to the third of these categories; Moyal-Sharrock's (2005) to the second and mine to the first. Of course people may disagree with this judgment. The point remains that, depending on the interests at issue, we may rank interpretations and chose among them in a principled way. Since my Moore and Wittgenstein is meant to be mainly a contribution in history of analytic philosophy, I would stand by it as a work in textual exegesis, even if I'm happy to acknowledge that other readings may be more valuable if judged by different standards. So, if an interpretation

i) doesn't have much textual evidence on its side; and/or

ii) it can be shown that it has to massively revise translations, which are otherwise generally correct, in order to be backed by evidence; and/or

\footnotetext{
A. Coliva $(\square)$

Department of Linguistic and Cultural Studies, University of Modena \& Reggio Emilia and COGITO, Via Università, 4, 41100 Modena, Italy

e-mail: annalisa.coliva@unimore.it
} 
iii) if it can be shown that it has to impute widespread inconsistencies to the author, which it recommends to rectify or correct; and/or

iv) if it can be demonstrated that it actually misunderstands the text,

it shouldn't be favored, from a merely historical point of view, notwithstanding its possible merits in other respects.

\section{Reply to Moyal-Sharrock}

With this in mind, let me address Danièle Moyal-Sharrock's extremely inspiring, yet challenging comment. Her main criticism concerns my understanding of hinges as both judgments and norms. In her view, these two functions are mutually exclusive and she actually thinks hinges are just norms, that we sometimes voice for merely heuristic purposes, even though, most of the time, they remain silent and display themselves only in action.

According to Moyal-Sharrock, when I talk of judgment in this connection, I have in mind bona fide judgment, i.e. the result of a conscious evaluation of evidence which leads to making up one's mind one way or the other with respect to $\mathrm{P}$. However, this isn't exactly what I had in mind in writing the book and I am sorry I wasn't clear enough about it. For I totally agree that meant this way, taking hinges as judgments would preclude them from being norms. In particular, I agree that if what one had to do in order to judge that there is a hand here, is to go through the evaluation of evidence for or against it, this would be enough to show that what we are presented with isn't a hinge but an ordinary empirical proposition, for which it makes sense to wonder whether it is the case or what evidence speaks in favor of it.

However, I am not convinced by Moyal-Sharrock's interpretation of the term "judgment", when used by Wittgenstein in his later writings, as meaning a purely instinctual, non-contentful reaction. Of course agreement in this kind of behavior is a condition or, better, a pre-condition for language and thought. But it would be really confused and confusing for Wittgenstein to call agreement in non-verbal, preconceptual reactions, "agreement in judgment".

What I meant by "judgment" is what I think Wittgenstein (1953) himself has in mind, for instance in PI 242, when he writes:

If language is to be a means of communication there must be agreement not only in definitions but also (queer as this may sound) in judgments. This seems to abolish logic, but does not do so.- It is one thing to describe methods of measurement, and another to obtain and state results of measurement. But what we call "measuring" is partly determined by a certain constancy in results of measurement.

Now, I suppose there is no issue that the kind of judgment Wittgenstein is alluding to here is something totally conscious and conceptual - after all it's the result of a deliberate process of measurement. So, the idea, I take it, is that in order for meaning to be possible it isn't enough to agree on (either verbal or ostensive) definitions, e.g. regarding the meaning of " $10 \mathrm{~cm}$ " or of "hand". It is necessary also to agree in judging that the side of the tiles in the kitchen is $10 \mathrm{~cm}$ long, when we measure it, or that a given object is a hand. If we didn't agree in these judgments, i.e. in these applications of our terms, defined the 
way they are, no definition would actually bestow a meaning onto these words. Of course sometimes we don't agree: we have to check whether the tile is actually $10 \mathrm{~cm}$ long, and we can disagree about whose measurement is correct, or whether a given object is a hand. Yet, if we always disagreed about such things, with no possibility of converging in our judgments, this would impugn the possibility of language and communication and, in a Wittgensteinian perspective, of thought as well. None of this, however, is of comfort to a communitarian view of meaning, I think. It simply exposes the grammatical connection between "rules" and "agreement in judgment".

So, the idea I put forward in the book is that there are judgments, whose content is propositional, and concerns objects, people and states of affairs, which, however, play a normative role, rather than a genuinely empirical one. They don't play an empirical role because they aren't subject to verification and control the way in which ordinary empirical judgments are. Nor are they open to sensible doubt, in ordinary circumstances, for that would call into question the fact that either the subject knows the meaning of, say, the word "hand", or the fact that he is cognitively lucid or perceptually reliable. Yet, they retain empirical content, precisely because they state how things are. They tell us that there is a hand here, that one's name is NN, that the Earth has been existing for a very long time, that nobody has been on the Moon, etc. Sometimes these judgments are based on evidence, for, after all, we see that there is a hand here; some other time they aren't, or, at least, as Moore would have it, we can't recall it anymore. After all, what precise evidence do we - lay people - have for the long existence of the Earth? The point is that even if in some sense they are based on evidence, on reflection such evidence owes its status to the very holding of the hinge in question. If we could doubt that there is a hand here, when we are in perfect lighting conditions, are awake and cognitively lucid, why should we trust our senses? Similarly, if we could doubt that the Earth has existed for a very long time, why should we trust geology that tells us otherwise? For everything that holds as a proof in geology owes its status to the assumption that the Earth has existed for a very long time. We could put the point by saying that whatever evidence we have for hinges it doesn't epistemically support them-i.e. it doesn't amount to a justification for them, since it presupposes them-, even though it may causally prompt us to judge them.

In the précis, I have explained the Janus-faced nature of hinges by appealing to the difference between the role and the content of a judgment, i.e. of a proposition ('Satz', in German, which I keep translating as 'proposition' and not as 'sentence', in conformity with the official translation): a judgment may have or retain empirical content while playing a normative role. It seems to me that there is nothing terribly mysterious or suspicious about this idea. Indeed it seems to me to square with some important passages Moyal-Sharrock herself draws attention to. Namely OC 318-20:

'The question doesn't arise at all.' Its answer would characterize a method. But there is no sharp boundary between methodological propositions and propositions within a method.

But wouldn't one have to say then, that there is no sharp boundary between propositions of logic and empirical propositions? The lack of sharpness is that of the boundary between rule and empirical propositions.

Here, one must, I believe, remember that the concept 'proposition' itself is not a sharp one. 
The idea, I take it, is precisely that, by the time of OC, Wittgenstein held the view that there is no sharp boundary between rules and empirical propositions, because there are propositions "about material objects" (OC 402) which, however, don't play an empirical function in context. Yet context can change, either synchronically or diachronically, and these propositions can acquire or re-acquire a purely empirical role. For instance, "Here is my hand" can cease to be a norm of evidential significance, because, after a car accident, it can actually be open to sensible investigation whether this limb I see next to me is in fact my hand. Similarly "Nobody has ever been on the Moon" can be liable to rational inquiry and may even turn out to be false if scientific progress allows for it.

This doesn't mean that in the meanwhile we have substituted those hinges with their empirical doppelgangers. Indeed there is no passage in On Certainty which, to the best of my knowledge, explicitly states the idea of doppelgangers and of unnoticed substitutions of hinges with ordinary empirical propositions. The idea of doppelgangers emerges only if one takes 'Satz' to mean 'sentence' and then takes the passages for instance around OC 95-99 to suggest that one and the same sentence can be used either to express an empirical proposition or else a norm. ${ }^{1}$ But those (and other) key passages actually suggest a different idea, when the ordinary translation is preserved. Namely, that "some propositions, of the form of empirical propositions" may be "hardened" so as to function "as channels" for ordinary empirical propositions and yet this relation can alter with time "in that fluid propositions"- not their doppelgangers - harden, and hard ones become fluid (OC 95). Indeed, for Wittgenstein, "the same proposition" (Satz) "may get treated at one time as something to test by experience, at another as a rule of testing" (OC 98). This is clearly the case with "Here's my hand", but also, diachronically, with "Nobody has ever been on the Moon". 2

Moyal-Sharrock is also particularly fond of the idea that the main message of $\mathrm{On}$ Certainty - indeed its revolutionary gist - is to press the view that at the bottom of our language games lie animal certainties. That is to say, non conceptual, merely instinctual ways of acting, which can sometimes be expressed in words, but only for heuristic purposes. The anti-skeptical import of animal certainty would be to expose not just the ineffectuality but also the categorial mistake of calling into question ways of acting. For they lack propositional and indeed conceptual content, are preconditions for sense, and can't, therefore, be sensibly doubted.

In the précis I rehearsed the reasons why I don't think animal certainty is a terribly new, or for that matter promising idea against skepticism. Hume had already proposed an albeit different form of naturalism and had correctly seen it not so much as a

\footnotetext{
${ }^{1}$ Notice, furthermore, that if 'Satz' were translated with 'sentence', the passages around OC 318-20 quoted before would hardly make sense.

2 If Wittgenstein had wanted to express the idea of doppelgangers, why didn't he write something like "the same sentence could sometimes be used to express something to test by experience and some other time a rule of testing"? Why did he have to be so convoluted as to write that the same 'Satz' - usually translated with 'proposition'- "may get treated at one time as something to test by experience, at another as a rule of testing"? Of course OC is a collection of notes, not revised for publication, but there is nothing fancy or out of reach for someone who had been trafficking for all his life with philosophical terminology in the idea of sentences and their property of expressing different things on different occasions, or in different languages.
} 
response but, rather, as a consequence of skepticism. Justifications come to an end and at bottom lie a-rational ways of acting which are forced on us by nature-let it be our psychological constitution or our more culturally determined second nature. The quest for reasons a skeptic is after can't be satisfied, just as skeptics maintain, and we have to rest content with our ingrained ways of acting. So, to repeat, this picture isn't new; nor is it a powerful weapon against skepticism. What would Wittgenstein's original contribution against skepticism be, then? Perhaps his insistence that sensible doubts must be backed by reasons, and that skeptical doubts aren't. But this idea, just by itself, wouldn't advance matters much further. After all, skeptics would allow that their doubts aren't like ordinary ones. Yet they would defend their legitimacy. I will come back to what I think is Wittgenstein's more complex response to skepticism shortly, in connection with another contribution that focuses exactly on that issue.

Let me then conclude my response to Moyal-Sharrock by addressing the issue of Wittgenstein's foundationalism. The term "foundationalism", in philosophy, describes a fairly precise epistemological position. Michael Williams (2005) has usefully reminded us of its main features in connection with an analysis of whether On Certainty can be seen as proposing a form of it. Accordingly, (i) foundations are universal; (ii) there must be criteria to tell them apart from what they ground; (iii) they must be independent of what they ground; (iv) the passage from grounds to what is grounded shouldn't require appeal to non-basic propositions. We could also add that (v) grounds should play an epistemically supporting role with respect to what is grounded by them; and (vi) that they should be epistemically more secure than what they ground.

As to (i), of course some of Wittgenstein's hinges are universal, but surely not all of them. "My name is AC" is a hinge for me, not for any other person, although it is to be expected that each person will have his own similar hinge-i.e."My name is NN". Regarding (ii), what plays the role of a hinge is contextually determined and we have to look at the practice-i.e. at how each specific language game is actually played - in order to determine what has the function of a hinge with respect to it. However, the very same proposition could play a different role in a different context. This is clearly the case with "Here is my hand", although the doppelganger view obscures this point, because it entails that those words actually express two different things and that context decides which one it is, but, whatever it is, it is either a rule or an empirical proposition once and for all. With respect to (iii), hinges, for Wittgenstein, aren't such because they are intrinsically epistemically secure or more secure than what they are supposed to ground (vi). Rather, they are kept fixed by our very practice, by what rotates around them. Regarding (iv), it should be noticed that hinges aren't eternal and can be demoted so as to acquire, or even re-acquire a purely empirical function. In particular, this can happen also because of empirical changes. This possibility is clearly illustrated by "Nobody has ever been on the Moon", since it has been re-immersed in the flux of empirical propositions and has been falsified by history. Contrary to (v), Wittgenstein's hinges don't play a supporting epistemic role with respect to what they ground, because they don't have any epistemic status. They are neither known nor certain in any traditional epistemic sense. They are norms which must stay put for our epistemic practices - those in which we acquire justifications and knowledge - to be possible. As opposed to (vi), hinges are certain, for Wittgenstein, but not in an epistemic sense. To repeat: they are certain because they 
play a normative role and make our epistemic practices possible. Therefore, nothing, at least in context, could actually speak against them because they themselves ground the possibility of acquiring any kind of evidence, even the one which should putatively speak against them. However, they aren't certain because they are epistemically more secure than anything else.

To conclude: the revolutionary force of Wittgenstein's On Certainty that MoyalSharrock wishes to express as a new form of foundationalism could, I think, be fully retained by actually maintaining the opposite. That is to say, by acknowledging that Wittgenstein wasn't a foundationalist, precisely because he was against the main tenets of that philosophical doctrine. That's why I ventured to say he was an anti-foundationalist, notwithstanding the numerous foundational metaphors interspersed in On Certainty. Still, I think Moyal-Sharrock and I agree on the tremendous significance that Wittgenstein's last notes can have for epistemology, because they provide both a somewhat revolutionary assessment of this area of philosophical inquiry, as traditionally practiced, and an alternative to some of its main tenets. An alternative that can be developed in various possible ways that have a crucial impact on how this discipline is practiced nowadays, as the work of Wright, Williams, and Pritchard testifies. ${ }^{3}$

\section{Reply to Boult and Pritchard}

The significance of On Certainty for current epistemology is excellently brought out by Cameron Boult and Duncan Pritchard in their contribution to this symposium. They make an admirable job at summarizing my interpretation of Wittgenstein's anti-skeptical strategies in OC, which are basically two. The first one claims that skeptical doubts are nonsensical-i.e. irrational - because they are based on the categorial mistake of raising doubts about norms of meaning and evidential significance, which are, in their turn, necessary in order to formulate any sensible doubt. The second one, in contrast, is more semantically oriented and has it that since meaningful doubts are only those that are based on grounds, skeptical ones are ipso facto nonsensical in a linguistic sense-i.e. they are meaningless. They retain an appearance of sense only because we project it onto them from ordinary contexts of doubt. They criticize my readings, however, for depicting the skeptic as an opponent, who can be shown to be irrational or only to seem to speak sense, while skepticism is more profitably addressed as a paradox.

I think there is something right and something wrong in their allegation. What is right is that, really, there are (or have been) very few skeptics around (possibly Pyrrho and his followers, Descartes in his First Meditation, Hume, Unger and not many more). So, any anti-skeptical strategy that merely showed such opponents wrong, in some sense or other, would have limited philosophical significance. What is wrong, however, is to suggest either that the paradox-understanding of skepticism is more valuable in order to make sense of what Wittgenstein says in OC - which is what I am mostly up to in my book-, or that what he actually says in OC can't be used to try

\footnotetext{
${ }^{3}$ My own work in epistemology is meant as a development of some Wittgensteinian ideas. See, in particular, Coliva (2011, 2012a, b; Coliva, Moderatism,transmission failures, closure, and Humane skepticism, unpublished, Coliva, Extended rationality, unpublished).
} 
and provide a solution to skeptical paradoxes. For, surely, Wittgenstein never speaks of skepticism as a paradox, nor does he bother to lay out its steps and show which ones are untenable. But, of course, nothing prevents us from trying to put what he says in that form. Indeed, I think this would be a valuable exercise, which I am happy to take up in the rest of my reply.

Boult and Pritchard stress that the paradox to which OC can be seen as providing a response is the Humean one, rather than the Cartesian one, ${ }^{4}$ which can be reconstructed as follows:

(1) In order warrantedly to believe that there is a hand here, you need warrantedly to believe that there is an external world. ${ }^{5}$

(2) You can't warrantedly believe that there is an external world, because any warrant you may get for it would depend on presupposing the existence of the external world; therefore

(3) You can't warrantedly believe that there is a hand here

The characteristic step of the Humean paradox is (2), which points out the epistemic circularity involved in any attempt to justify our belief in the existence of an external world, at least if the justification has to be perceptual. The idea is that such an effort would involve something like Moore's proof:

(I) Here is my hand;

(II) If there is my hand here, there is an external world; therefore

(III) There is an external world

Yet, any perceptual warrant one may have for (I) would depend on taking (III) for granted (and on taking for granted that one's sense organs are working reliably). Hence, such an argument couldn't provide one with a first warrant to believe its conclusion. Thus, step (2) of the Humean argument would hold and its skeptical conclusion (3) follow.

The other noticeable aspect of the Humean argument is that it relies on the Principle of Closure for epistemic operators, insofar as lack of warrant for a proposition entailed by another one would, by contraposition, deprive the latter of warrant too.

Now, I take it that Wittgenstein's observations in OC, as I read them, can be seen as addressing these two key points. According to Wittgenstein, it is indeed right to hold that an argument such as Moore's would be epistemically circular and therefore epistemically ineffective. This, however, leads to his embracement of (2), contrary to what Wright (2004) and Williams (2004) maintain. ${ }^{6}$

Notice, however, that the reason why, on my interpretation, Wittgenstein would subscribe to (2) is slightly different from the kind of usual motivation offered at least

\footnotetext{
${ }^{4}$ The Cartesian paradox can be roughly put as follows: (1) If you don't know that you aren't dreaming, you can't know that there is a hand here (or any other ordinary empirical proposition). (2) You can't know that you aren't dreaming; therefore (3) you can't know that there is a hand here. In fact OC speaks also to the Cartesian paradox, by holding that although we can't know that we aren't dreaming, the hypothesis that we were is self-defeating and it merely retains an appearance of sense because we project it onto it from ordinary contexts of employment of those words. I discuss the issue in chapter 3 of Moore and Wittgenstein. ${ }^{5}$ Or that your sense organs are working reliably, or that you aren't prevented from causal interaction with the physical world through dreaming or envatment, etc.

${ }^{6}$ In the précis and in chapter 3 of Moore and Wittgenstein I have already exposed why I think their interpretations, no matter how different they are both in detail and in substance, actually depend on a similar misunderstanding of the relevant passages in OC.
} 
since Wright's (1985) reconstruction. For, as we have just seen, Wright thinks that Wittgenstein would claim that the Moorean argument is circular because warrant for (III) would be needed in order to have a perceptual warrant for (I). However, since for Wittgenstein (III) would certainly be unwarrantable, the circularity in the Moorean argument would depend on the fact that (III) as such would have to be presupposed in order to have warrant for (I).

What this entails is that Moore's argument would be circular for Wittgenstein, yet not exactly because of what, after Wright, has become known as "failure of transmission of warrant", but because of a phenomenon closely related to it, even though slightly different from it. In my own writings on the topic (Coliva 2011 in particular and Coliva, Moderatism,transmission failures, closure, and Humane skepticism, unpublished, Coliva, Extended rationality, unpublished), I have called them "transmission failure 1" and "transmission failure 2", respectively. Readers interested in their more precise formulation can find it in the following footnote. ${ }^{7}$

So (2) does hold for Wittgenstein, as I read him. Yet, (3) wouldn't follow, for him, because, in effect, his views entail that Closure doesn't hold unconditionally. ${ }^{8}$ For, according to him, hinges are neither known nor unknown, warranted or unwarranted; yet this doesn't preclude the possibility of acquiring warrants and even knowledge of ordinary empirical propositions such as "Here is a hand". 9 So, I take it, some denial of Closure is in play at least in the following sense: if the propositions entailed do have a normative, rather than an empirical role, then they aren't up for epistemic appraisal at all. That is to say, they can't be assigned either a positive, or a negative epistemic status. They can't be known or warranted, contrary to what Moore held; or be considered epistemically defective because they can't be known or warranted, as skepticism would recommend.

Notice, however, that by having an empirical content, though not an empirical function, hinges can be entailed by other propositions, which can be warranted or even known, without thereby having to possess the same epistemic status of the propositions which entail them. ${ }^{10}$ By contraposition, the fact that they lack such an

\footnotetext{
${ }^{7}$ Transmission failure 1: An argument fails to transmit warrant from its premises to the conclusion (in way 1) if (and only if) warrant for the conclusion is already needed in order to have warrant for its premises in the first place.

Transmission failure 2: An argument fails to transmit warrant from its premises to the conclusion (in way 2) if (and only if) this very conclusion needs already to be assumed in order to have warrant for its premises in the first place.

${ }^{8}$ It is important to stress that the denial of Closure is limited to entailments which have hinges as consequents, not to any kind of possible entailment. For instance, if I know that the book on my desk has 100 pages and I know that this entails that it has less than 200 pages, I will also know that the book has less than 200 pages.

${ }^{9}$ Here I will pass over the fact that "Here's a hand" in the circumstances of Moore's proof is a hinge for Wittgenstein; hence something in whose connection "I know" can only be meant grammatically. So, in effect, the exemplification I have given of the Human argument would be totally objectionable from a Wittgensteinian point of view. Notice, however, that it could be safely rendered by substituting "Here is a hand" with a proposition which is empirical by Wittgenstein's lights, e.g. "There are half million people in this town".

${ }^{10}$ Ordinary framework readings, which claim that hinges are just norms and lack any empirical content, would deny this and would therefore interpret the relevant remarks in OC as compatible with the retention of Closure. They would agree, however, that hinges can't be known or warrantedly believed and yet, ordinary propositions, which are believed or known by holding them fast, could indeed retain such positive epistemic status.
} 
epistemic status doesn't make the empirical propositions which entail them any less known or warranted. Hence, (3) doesn't follow from (1) and (2), in particular because (1) itself involves Closure and this principle doesn't hold unconditionally.

One problem with this interpretation is that figuring within an entailment requires being truth-assessable. Now, there is no denying that Wittgenstein's remarks on this issue, in OC, are ambivalent and that framework readings will have to deny the truthassessibility of hinges. I have the impression, however, that there are two different notions of truth in play in OC. One, more epistemically-oriented, which prevents hinges from being true (or false), for they can't be warranted or justified; and one more minimalist, ${ }^{11}$ which may apply to hinges too, for it doesn't ascribe any substantial property to them (OC 80-3, 193, 206). Rather, it merely helps account for some platitudes. For instance, that hinges can be embedded in wider propositional contexts, involving entailment; or that if $\mathrm{P}$ is true than things are as $\mathrm{P}$ says they are. Indeed on this understanding, even the negation of a hinge is meaningful. Yet, it would be nonsense to judge its negation, i.e. to hold that it is the case in the relevant circumstances.

So we can actually appreciate how, on my proposed understanding of hinges, Wittgenstein would have offered motivations totally different — and, to my mind, more convincing - than those put forward by Dretske $(1970,2005)$ and Nozick (1981) to deny the unconditional validity of Closure, ${ }^{12}$ well before them. Moreover, he would have had a story to tell as to why this shouldn't lead to any "abominable conjunction", in Keith DeRose's (1995) memorable formulation. For Wittgenstein wouldn't be committed to simply saying "I know/warrantedly believe that there is a hand here, but I don't know/warrantedly believe that the external world exists". Rather, he would be in a position to say something like "I know/warrantedly believe that there is a hand here, but I don't know/warrantedly believe that the external world exists. Yet this is the unwarrantable assumption, whose status is normative, from which my empirical knowledge and warranted beliefs depend". ${ }^{13}$

Still, there is more to the Wittgensteinian strategy and indeed something which speaks to the kind of epistemic vertigo Boult and Pritchard think one would succumb to after being exposed to skepticism. Now, it is interesting to notice that they describe this situation as a kind of vertigo and therefore of phobia. Yet phobias, though part of human experience, aren't, luckily, necessarily part of the human condition. Indeed they can often be cured and it is not by chance that Wittgenstein conceived of his own way of philosophizing as a kind of therapy. Notice, furthermore, that phobias are within us. Similarly, the philosophical therapy which OC can be seen as proposing would cure the skeptic in us. That is to say, the temptation to think that even if we are aware that our most basic certainties are epistemically ungrounded and yet our ordinary empirical practices are perfectly secure, there is something disturbing in recognizing the ungroundedness of our believing.

\footnotetext{
${ }^{11}$ Cf. fn. 8 in the précis. Cf. Williams 2004, although he develops this idea in ways which I would resist. For a discussion, see chapter 3 of Moore and Wittgenstein.

${ }^{12}$ As is well-known, their respective analyses of knowledge in terms of relevant alternatives and sensitivity, have been forcefully criticized in the ensuing literature.

${ }^{13}$ For a discussion of how best to respond to the challenge raised by DeRose, see Coliva (2012a and Coliva, Extended rationality, unpublished), in which also Pritchard's (2005) and Sosa's (2000) replies are considered and assessed.
} 
The therapeutic elements would come from the recognition that a doubt that targets propositions whose function is normative and that must be in place in order to gather any kind of evidence - also the evidence which would allegedly speak against them - is irrational in the precise sense of not being backed by reasons. So why take it seriously? Furthermore, the therapy would reach even more radical results if one added that doubts which, like skeptical ones, aren't motivated at all, would actually be meaningless. The very question "Couldn't after all be the case that I am merely dreaming that there is an external world (or that there is my hand here)?" would, in a Wittgensteinian perspective, only retain an appearance of sense, but it would actually have none. By being reminded of this twofold kind of nonsense, we should, little by little, manage to develop a frame of mind in which we would no longer be assailed by the kind of epistemic vertigo caused by exposure to skeptical arguments.

\section{Reply to Tripodi and Kusch}

In their complex and thought-provoking contributions, Paolo Tripodi and Martin Kusch raise the concern that Wittgenstein was an epistemic relativist of sorts. By contrast, in the book and elsewhere (Coliva 2010a, b), I have maintained the opposite. Before addressing their criticisms, however, let me stress that my aim was, first and foremost, to bring to light the intricacy of Wittgenstein's views on the matter. In particular, the fact that even if plenty of remarks, both in On Certainty and in other of his later writings, seem to support a kind of relativist position, they are much less univocal than what they look like at first sight. To be less univocal doesn't mean to clearly sustain the opposite, but simply to be open to different interpretations. Of course I am aware that the querelle between supporters of these opposite readings isn't new. ${ }^{14}$ Yet, it seems to me that the idea that Wittgenstein was a sui generis kind of relativist, if not shared by the majority of Wittgensteinian scholars, is at least the vulgata that has trespassed the narrow boundaries of that scholarship to become a kind of commonplace in other, more theoretically-oriented quarters of philosophy. ${ }^{15}$

Now, Tripodi thinks that Wittgenstein did recognize the existence of two, incompatible epistemic systems, at least when religious beliefs are at issue, which would return opposite verdicts on some key credence. On the one hand, there is the system which confers justification to propositions by means of empirical evidence; whereas, on the other, there is the one which derives justification for them from the "evidence of the heart". The latter comes either from "wonder at the existence of the world", or from "the experience of feeling absolutely safe" as well as from its opposite, i.e. the experience of "distress and absolute loneliness"; or else from the "recognition of sin",

\footnotetext{
${ }^{14}$ I should stress that I usually refer to the works actually used in my writings, which aren't, of course, the only ones I am aware of on the subject-matter at issue. I understand that this practice may unfortunately generate the impression, to which Martin Kusch succumbed, that I either ignore or diminish the relevance of other contributions to the relevant literature, even though neither is the case. Let me also point out that my writings on Wittgenstein's alleged relativism were a reaction, originated when I was attending to the Italian translation of Paul Boghossian's Fear of Knowledge, against his cavalier inclusion of Wittgenstein in the relativist club.

15 This is the view shared not only by Boghossian (2006) and Rorty (1979), but also by several Italian philosophers on either side of the so-called "new-realist/anti-realist" divide, such as Vattimo and Marconi.
} 
or, finally, from taking everything that happens to one as a reward or punishment. Tripodi makes a remarkable job at elucidating how sensitive Wittgenstein was to this latter kind of evidence. Yet, it seems to me that to think of it as constituting an alternative epistemic system would be a mistake. A mistake which perhaps Wittgenstein himself made, but a mistake nonetheless. If so, however, his own writings couldn't genuinely support a relativist stance. For the evidence of the heart in fact doesn't make the truth of the propositions it prompts us to believe any more likely; while empirical evidence does precisely that. If it did and one, like Wittgenstein, were sensitive to it, it should rationally compel one to embrace a given dogma. But it is note-worthy that Wittgenstein himself never felt so compelled. The evidence of the heart is in fact a mix of psychological experiences, which may somewhat cause one to embrace a religious stance, or even a dogma — like the one of the Last Judgment — but that don't make the proposition "There will be a Last Judgment" (or any other problematic religious credence) any more likely true. Of course the believer will think that the propositions in question are true, but this is just due to the obvious fact that to believe that $\mathrm{P}$ means to hold $\mathrm{P}$ true. So the evidence of the heart amounts to a set of pragmatic reasons - broadly understood - that may induce belief in a subject, but it doesn't give rise to epistemic reasons - that is, to reasons that actually make the truth of $\mathrm{P}$ any more likely and that necessitate adherence to them, on pain of irrationality. Hence, I am not persuaded that by reverting to Wittgenstein's writings on religious belief one may find the seeds of a genuinely epistemically relativist position.

Turning now to Kusch's commentary, I think his nine-fold analysis of relativism mostly makes explicit what is already contained in the kind of more succinct analysis I myself have proposed, not only in my writings on Wittgenstein's putative relativism, but also in Coliva (2009). ${ }^{16}$ Explicitness is a virtue and so I applaud of it. Yet, there are some conditions listed by Kusch that I don't think are essential to the view. For instance, if contingency is meant to convey the idea that one's favored epistemic system is the result of being exposed to the vagaries of one's time, I think it is not a necessary feature of relativism. Even less if contingency aims to suggest some kind of historicism. For nothing, from a relativist view-point, would preclude the possibility of embracing very idiosyncratic epistemic systems, one has made up for oneself, as it were. Similarly, tolerance is more the desired consequence of relativism than one of its constitutive conditions. For, in a relativist vein, one may acknowledge that there is no rational way of choosing among systems and yet think that pragmatic reasons might enforce such a choice, which will then have to be secured through a-rational means. Also, I am not persuaded by non-appraisal. It seems to me to go against the evidence, for people do often assess other epistemic systems. Be that as it may, it is

\footnotetext{
16 1) Non-absolutism: the denial of absolutism, that is to say, of the idea that there are predetermined truths and values, which are given independently of our existence and that we can only discover or recognise, if they are somehow presented to us. 2) Relativization: the value of a parameter X-let it be concepts, facts, truth, knowledge, justification and ethical and aesthetic values - is relativized to another parameter Y, which can in turn assume different values - such as languages, conceptual schemes, descriptions, cultures, subjective standards of evaluation, ethical and aesthetical systems, and so on. 3) Multiplicity: the values of the parameter $\mathrm{Y}$ to which $\mathrm{X}$ is relativized - once the domain on which $\mathrm{Y}$ can range has been fixed-are many and diverse. 4) Difference: the values of $Y$ to which $X$ is relativized produce different values of $X$. 5) Incompatibility: the different values of $X$ are incompatible; 6) Equal validity: the different and incompatible values of $\mathrm{X}$, are all equally legitimate.
} 
difficult to see why it should be a constitutive feature of relativism, for there is nothing in relativism which prevents assessment. It is just that a relativist will have to claim that any appraisal will necessarily be biased, being a reflection of the specific epistemic system subscribed to by the judging subject. Finally, I am confused about the relationship between non-neutrality and equality. Equality-metaphysically speaking - is a consequence of the fact that there is no one single epistemic system which is absolutely correct. Hence, from a metaphysical point of view, various possible and incompatible epistemic systems should all be on a par, in that none of them would be more intrinsically correct than its competitors. Yet, obviously, evaluations are made by subjects who, willy-nilly, subscribe to one particular epistemic system and can't therefore make a neutral assessment. Notice, moreover, the peculiarity of making equality less relevant to relativism than non-neutrality. For, if equality has to go, what would prevent one from claiming, in a realist spirit, that, after all, there is one correct epistemic system and that the other ones are simply mistaken, notwithstanding their widespread acceptance in some quarters?

Let me now address Kusch's criticisms. First, regarding the passages in OC on the possibility of going to the Moon, I agree they aren't univocal. But while Kusch thinks that by discussing the relevance of evidence to the possibility of changing one's mind Wittgenstein was merely exposing our instinctive reaction, while not condoning it from a philosophical point of view, I would say that he was indeed expressing his philosophical view-point on the issue and then remark that we should feel very distant from someone who didn't respond to it the way we do (cf. OC 108).

Second, a similar tension is present between the passages on the odd woodsellers in the Remarks on the Foundations of Mathematics (1967/1978) and the ones in the Lectures on the Foundations of Mathematics, (1976) as Kusch rightly notices. But, again, from reading the latter in context, I don't get the impression that Wittgenstein is condoning their practice from an epistemic point of view. For the general background is a discussion of the point-not the correctness from an epistemic point of view - of doing things one way or the other. At p. 202, for instance, it is clear that Wittgenstein regards their practice as a way of "giving wood away" and claims that there is nothing wrong with doing that, meaning that, from a pragmatic point of view, the aim of selling wood could either be that of (mainly) making money, or a totally different one. That's why, on my reading, Wittgenstein ends up writing, on p. 204:

Suppose I gave you a historical explanation of their behavior: (a) These people don't live by selling wood, and so it doesn't matter much what they get for it. (b) A great king long ago told them to reckon the price of wood by measuring just two dimensions, keeping the height the same. (c) They have done so ever since, except that they later came not to worry about the height of the heaps. Then what is wrong? They do this. And they get along all right. What more do you want?

So the idea is that a practice is what it is and it often has a point. Yet, had the latter been different, the practice too would have been dissimilar. Either way, it would be legitimate, given its ends. But this doesn't mean that, given the end of determining the quantity of wood irrespective of its price, our particular ways of measuring wood are on a par. 
Notice, moreover, that this is the kind of contingency-i.e. the contingency of pragmatic ends - that this exercise in imagination aims to familiarize us with. Having that in mind, I claimed that at least the possibility of different concepts - yet not their different actual content — would become intelligible to us. So, from within our worldpicture our concepts are indeed necessary, as Kusch rightly notices. Yet, this doesn't mean that they are metaphysically grounded. And this is, in a nutshell, the kind of epistemic anti-foundationalism I think Wittgenstein was propounding, together with an anti-realist view of concepts.

One key concept which, in my reading of OC, is individuated by the epistemic practice of acquiring and assessing empirical evidence for or against a given proposition, is the concept of epistemic rationality. That's why I also put forward the idea that Wittgenstein could be labeled an "internal rationalist". But to recognize the fact that concepts are what they are because of the practice that helps individuate them isn't to subscribe to any naturalist position. For concepts determine what we can or can't conceive of. So they retain a normative, necessary aspect, despite their dependence on a practice, which could have been different from what it in fact is, even though, from within our Weltbid, we can't really think of how. ${ }^{17}$

Finally, concerning the discussion of the relationship between science and magic, I agree that Wittgenstein wouldn't consider science, taken as such, as superior to magic. However, the reasons why he wouldn't, don't seem to me to speak in favor of the view that magic would be, for him, a legitimate epistemic system genuinely alternative to ours. If that were the case, why should he then insist on the commonalities between "us" and "them" by stressing that their knowledge of nature isn't substantially different from ours? What he should have said instead, if that had been his general frame of mind, is that these two ways of knowing nature are different and incompatible, yet equally legitimate. Facing this puzzle I have therefore proposed to explain why Wittgenstein was so sensitive to magic by reference to the fact that it would speak to the final causes of phenomena in a way in which no science, either primitive or mature, would do. Connectedly, I have proposed to understand Wittgenstein's criticisms as directed to scientism rather than to science itself-i.e. to the idea that the sole kind of explanation of phenomena, even of anthropological ones, should be fashioned on the model of causal scientific explanations and that science's attention merely to efficient causes should little by little substitute the human tendency to look for final ones too.

\section{Reply to Leonardi}

I would now like to address Paolo Leonardi's sympathetic defense of Moore's position against Wittgenstein's and his attempt at rapprochement between their respective views regarding common sense truisms/hinges. I will start by discussing the latter.

I think Leonardi is absolutely right to point out that Wittgenstein's position is more hesitant than I make it seem in the book. In the précis I have put forward more explicitly than in the book an interpretation of hinges that sees them as Janus-faced, in

$\overline{{ }^{17} \text { Preserving its ends, of course. }}$ 
that they would have a descriptive content and yet a normative function. Moreover, in my reply to Boult and Pritchard I have actually made room for the idea that hinges could be true in a minimal sense. Even so, I personally think that this view shouldn't incline us to see them as contingent a priori truths, in any robust sense of the term. For they don't tally with a given reality, nor do they describe the transcendental structure of experience. Rather, they determine the conditions of meaning and of evidential significance, and by so doing we may find it inescapable to say that things are as they say they are. Furthermore, apart from "Water boils at $100{ }^{\circ} \mathrm{C}$ " (OC 293), Wittgenstein's hinges don't look like definitions of units of measurement. "The Earth has existed for a very long time", "Nobody has ever been on the Moon" look more like ordinary empirical propositions, with a descriptive content, which, however, have been removed from doubt and inquiry. So, they are synthetic - they tell us something about the world-, yet they are somewhat a priori, because they aren't epistemically derived from experience. Yet they aren't synthetic a priori truths, in any metaphysically robust sense of the word. As one may put it, they play the role of synthetic a priori norms of evidence and inquiry.

As to Leonardi's commendable reading of Moore, I am not sure whether, or exactly where we disagree. I agree that Moore's defense of common sense and proof of an external world are philosophically sophisticated, despite their ingenuous appearances. I agree that his common sense truisms play the role of foundational truths and I would add that this is a significant philosophical achievement, since it construes foundations in a novel and insightful way, with respect to how they had been conceived throughout the philosophical tradition up to that point. For Moore didn't revert to usual a priori truths or to basic experiences and/or beliefs. That's also what captivated Wittgenstein, in my view. I also agree with Leonardi that there are significant differences between the truisms listed in the 1925 paper and the kind of premise from which Moore's proof starts in his 1939 essay. The latter isn't perspectival, while the former are. Finally, I do agree with Leonardi that Moore's response to skepticism is more insightful than it may seem at first sight. If the skeptical challenge is to show that we have knowledge of something regarding physical objects in our environment, then "Here is my hand", in the conditions of Moore's proof, or "I am a human being" would be natural candidates.

What I think is wanting in Moore's strategy is (i) the idea that from such a piece of knowledge we could actually prove the knowledgeable existence of the external world; and (ii) the fact that the skeptical problematic is exhausted by the first-order issue of whether we have knowledge of some specific truths about the material world. Perhaps it is on these issues, but particularly on the second, that Leonardi and I disagree.

Regarding (i), the (warranted) existence of the external world seems to be presupposed by having knowledge of specific empirical truths, such as "Here is my hand". Hence, a proof which proceeded from such a premise and aimed at proving that there is an external world, thereby aiming at giving us knowledge of it, would be circular. Thus, it wouldn't be cogent and would consequently fail to prove what it aimed to prove.

Concerning (ii), I think that even if we granted Moore knowledge of "Here is my hand", achieved by looking at his hands in good lighting conditions, when awake and cognitively alert, this would by no means answer the challenge of proving that he 
does have that piece of knowledge. For, in order to do that, he should prove - and not just take for granted-that he isn't dreaming, that his sense organs are working reliably, etc. Indeed, Moore himself candidly admitted that he couldn't prove such a thing (1939, p. 149). He interestingly insisted that this wouldn't impugn his firstorder knowledge. Yet, it remains that he had no reply to this further skeptical challenge. That's also why, in the first chapter of Moore and Wittgenstein-which perhaps it'd better have been titled Wittgenstein and Moore, if one were to follow Leonardi's suggestion-I ventured to say that Moore somehow anticipated the typically externalist move of divorcing possession of knowledge from the ability of proving it. Moreover, I suggested that his strategy would have benefited from integrating that move with an analysis of the skeptical problematic, aimed at showing that it is either illegitimate or else answerable, perhaps by means of so-called "bootstrapping arguments". Much contemporary epistemology that can be seen as developing at least some of Moore's proto-externalist insights goes precisely in this direction. $^{18}$

\section{Conclusions}

As I wrote in the Introduction of Moore and Wittgenstein, I think these two philosophers are classics in epistemology not because they had the last word on some of the central issues of this area of philosophy, but because they can be seen as at least hinting at a number of problems and possible solutions, which are at the core of our discipline, even as is practiced nowadays. That's why their study can make us better aware of the kind of tradition we belong to and help us develop our own views in more interesting and promising ways. That's the secondary aim I had in mind when writing the book - while its primary goal was that of offering a faithful renditions of their positions. I hope this symposium will be yet another step in both these directions. Surely I learnt a lot from its contributors, whom, in closing, I would like to thank once more for their inspiring comments.

\section{References}

Boghossian, P. (2006). Fear of knowledge. Against constructivism and relativism. Oxford: OUP.

Cohen, S. (2002). Basic knowledge and the problem of easy knowledge. Philosophy and Phenomenological Research, 65(2), 309-329.

Cohen, S. (2005). Why basic knowledge is easy knowledge. Philosophy and Phenomenological Research, $70(2), 417-430$.

Coliva, A. (2009). I modi del relativismo. Roma-Bari: Laterza.

Coliva, A. (2010a). Moore and Wittgenstein. Scepticism, certainty and common sense. London: Palgrave Macmillan.

Coliva, A. (2010b). Was Wittgenstein an epistemic relativist? Philosophical Investigations, 33(1), 1-23.

Coliva, A. (2011). Varieties of failure (of warrant transmission-what else?!). Synthese, online first doi:10.1007/s11229-011-0006-6.

Coliva, A. (2012a). Scetticismo. Dubbio, paradosso, conoscenza. Roma-Bari: Laterza.

\footnotetext{
18 There is a growing literature on this issue, I will merely mention Cohen (2002, 2005), Kornblith (2009), Sosa (2007, 2009), Vogel (2000).
} 
Coliva, A. (2012b). Moore's proof, liberals and conservatives. Is there a third (Wittgensteinian) way? In A. Coliva (Ed.), Mind, meaning and knowledge. Themes from the philosophy of Crispin Wright (pp. 323351). Oxford: Oxford University Press.

DeRose, K. (1995). Solving the skeptical puzzle. Philosophical Review, 104(1), 1-52.

Dretske, F. (1970). Epistemic operators. The Journal of Philosophy, 67(24), 1007-1023.

Dretske, F. (2005). Is knowledge closed under known entailment? The case against closure. In M. Steup \& E. Sosa (Eds.), Contemporary debates in epistemology (pp. 13-26). Oxford: Blackwell.

Kornblith, H. (2009). A reliabilist solution to the problem of promiscuous bootstrapping. Analysis, 69(2), 263-267.

Moyal-Sharrock, D. (2005). Understanding wittgenstein's on certainty. London: Palgrave Macmillan.

Moore, G. E. (1939). Proof of an external world. In Philosophical papers (pp. 127-150). London: George Allen and Unwin, 1959.

Nozick, R. (1981). Philosophical explanations. Cambridge: Harvard University Press.

Pritchard, D. (2005). Epistemic luck. Oxford: Oxford University Press.

Rorty, R. (1979). Philosophy and the mirror of nature. Princeton: Princeton University Press.

Sosa, E. (2000). Skepticism and contextualism. Philosophical Issues, 10(1), 1-18.

Sosa, E. (2007). A virtue epistemology. Apt belief and reflective knowledge vol. I. Oxford: Oxford University Press.

Sosa, E. (2009). Reflective knowledge. Apt belief and reflective knowledge vol. II. Oxford: Oxford University Press.

Vogel, J. (2000). Reliabilism levelled. The Journal of Philosophy, 97(11), 602-623.

Williams, M. (2004). Wittgenstein, truth and certainty. In M. Kölbel \& B. Weiss (Eds.), Wittgenstein's lasting significance (pp. 249-284). London-New York: Routledge.

Williams, M. (2005). Why Wittgenstein isn't a foundationalist. In D. Moyal-Sharroch \& W. H. Brenner (Eds.), Readings of Wittgenstein's on certainty (pp. 47-58). Basingstoke: Palgrave Macmillan.

Wittgenstein, L. (1953). Philosophical investigations. Oxford: Blackwell.

Wittgenstein, L. (1967/1978) Remarks on the foundations of mathematics. Oxford, Blackwell.

Wittgenstein, L. (1969). On certainty. Oxford: Blackwell.

Wittgenstein, L. (1976). Wittgenstein's lectures on the foundations of mathematics, Cambridge 1939. Chicago: Chicago University Press.

Wright, C. (1985). Facts and certainty. Proceedings of the British Academy, 71, 429-472.

Wright, C. (2004). Wittgensteinian certainties. In D. McManus (Ed.), Wittgenstein and scepticism (pp. 22-55). London-New York: Routledge. 